\title{
Pós-modernidade nos estudos organizacionais: equívocos, antagonismos e dilemas
}

\author{
Postmodernity in organizational studies: mistakes, antagonisms, and dilemmas
}

Eloisio Moulin de Souza ${ }^{1}$

\begin{abstract}
Resumo
Este artigo intenta analisar aspectos ontológicos e epistemológicos relacionados à pós-modernidade, para entender se a pós-modernidade consiste em ontologia, epistemologia ou ambas, verificando, assim, os possíveis equívocos em relação à sua utilização nos estudos organizacionais. Para cumprir este intento, fez-se necessário também analisar as principais diferenças entre pós-modernidade, estruturalismo e pós-estruturalismo. Salienta-se que, de forma geral, a definição de pós-modernidade oscila entre dois polos: (1) período histórico, época e éthos social; (2) corrente teórica, epistemologia, tradição intelectual e filosófica. Por fim, observam-se os seguintes equívocos nos estudos organizacionais relacionados à pós-modernidade: (1) definir pós-modernidade como movimento teórico, corrente de pensamento; (2) tratar pós-estruturalismo como sinônimo de pós-modernidade, e vice-versa; (3) atribuir características à pós-modernidade que na realidade dizem respeito ao pós-estruturalismo; e (4) desconsiderar o estruturalismo em suas análises sobre a pós-modernidade.
\end{abstract}

Palavras-chave: Pós-modenidade. Pós-estruturalismo. Estruturalismo. Epistemologia. Ontologia.

\begin{abstract}
This paper aims at analyzing ontological and epistemological aspects related to postmodernity, to understand if postmodernity consists of ontology, epistemology or both of them, verifying, thus, possible misunderstandings with regard to its use in organizational studies. To accomplish this task, there is also a need for analyzing the main differences between postmodernity, structuralism, and post-structuralism. One notices that, generally, the definition of postmodernity oscillates between two poles: (1) historical period, time, and social ethos; (2) theoretical perspective, epistemology, intellectual and philosophical tradition. Finally, one observes the following mistakes in the organizational studies related to postmodernity: (1) to define postmodernity as a theoretical movement, a school of thought; (2) to treat post-structuralism as a synonym of postmodernity, and vice-versa; (3) to assign characteristics to postmodernity that actually concern post-structuralism; and (4) to disregard structuralism in their analysis on postmodernity.
\end{abstract}

Keywords: Postmodernity. Post-structuralism. Structuralism. Epistemology. Ontology.

\section{Introdução}

Entender o que é pós-modernidade não é algo simples. Existem diversos autores que tentaram definir pósmodernidade, mas não há um consenso sobre essa definição. Alguns autores nem utilizam a expressão pósmodernidade para definir o momento contemporâneo que estamos vivendo. Por exemplo, Bauman (1998, 2005) denomina de modernidade líquida, Giddens $(1991,2002)$ usa a expressão modernidade tardia,

1 Doutor em Psicologia pela Universidade Federal do Espírito Santo; Professor Adjunto do Departamento de Administração Universidade Federal do Espírito Santo. Endereço: Av. Fernando Ferrari, 514, Goiabeiras, CEP 29075-910, Vitória - ES, Brasil. Email: eloisiomoulin@gmail.com 
Jameson (1991), capitalismo tardio e Harvey (1992), sociedade pós-industrial. O fato de não ser fácil encontrar uma definição clara de pós-modernidade nos estudos sociológicos contribui demasiadamente para que os estudos organizacionais não apresentem em seus textos uma definição de pós-modernidade inequívoca.

De forma geral, a definição de pós-modernidade oscila entre dois polos opostos e autoexcludentes: (1) período histórico, época e ethos social, ontologia, (2) corrente teórica, epistemologia, tradição intelectual e filosófica de pensamento. Assim, enquanto alguns autores trabalham pós-modernidade como ontologia, não a restringindo apenas ao campo do conhecimento, outros entendem pós-modernidade como epistemologia, ou seja, corrente teórica de pensamento. Além disso, as diferenças existentes entre os conceitos de pósmodernidade e pós-estruturalismo não estão claras nos trabalhos organizacionais sobre o tema, o que alimenta ainda mais possíveis equívocos.

Vieira e Caldas (2006) salientam que existem poucos pesquisadores que trabalham com uma perspectiva pós-moderna nos estudos organizacionais brasileiros, fato que empobrece muito o debate sobre o tema no Brasil. Nesse sentido, esse artigo pretende analisar aspectos ontológicos e epistemológicos relacionados à pós-modernidade nos estudos organizacionais, intentando verificar possíveis equívocos em sua utilização, analisando se pós-modernidade é uma ontologia, epistemologia ou ambos, apresentando também as principais diferenças existentes entre pós-modernidade e pós-estruturalismo. Vale ressaltar que não se pretende aqui analisar o significado semântico da palavra pós-modernidade, mas sim aspectos ontológicos e epistemológicos relacionados à pós-modernidade.

Para cumprir o seu intento, o artigo foi organizado da seguinte maneira: primeiramente serão apresentados os conceitos de pós-modernidade presentes nos estudos sociológicos, para logo em seguida se analisar as diferenças existentes entre pós-estruturalismo e pós-modernidade. Posteriormente serão apresentados aspectos relacionados ao uso da pós-modernidade nos estudos organizacionais, bem como os principais conflitos e equívocos presentes nessa utilização.

\section{Os Significados de Pós-Modernidade}

Realmente entender o que é pós-modernidade não é uma tarefa simples, pois não existe consenso entre autores sobre o que seria pós-modernidade. Sarup (1996) afirma que a partir da década de setenta tem ocorrido grandes mudanças sociais e estas mudanças trouxeram novas formas de se vivenciar tempo e espaço. Para Sarup (1996, p. 94, tradução nossa), "Existe algum tipo de relação necessária entre o surgimento das formas culturais na pós-modernidade e a emergência de modelos mais flexíveis de acumulação de capital, e uma nova rodada de compressão tempo-espaço na organização do capitalismo". Sarup (1996) defende que o significado de pós-modernidade pode ser explicado no nível cultural, implicando repúdio ao movimento moderno com suas pinturas abstratas expressionistas, seu estilo internacional de arquitetura e sua filosofia existencialista; bem como no nível político, atuando como um contundente ataque ao marxismo, ao rejeitar o modelo de autenticidade e inautenticidade, a oposição semiótica entre significante e significado, o modelo freudiano de manifestação latente e a busca pela essência. Observa-se assim que para Sarup (1996) pós-modernidade está relacionada com cultura, economia, conhecimento e social, não colocando uma hierarquia entre estes.

Harvey (1992) se aproxima em dois aspectos apontados por Sarup (1996) ao defender que a pósmodernidade está implicada com mudanças na economia e nos saberes. Ele demonstra que o mundo está mudando rapidamente e que o resultado dessas mudanças tem sido a produção de fragmentação, de insegurança, de efemeridade, desenvolvidas dentro de uma economia altamente unificada de fluxo de capital. $\mathrm{O}$ autor afirma que pós-modernidade é uma rejeição a todo projeto da modernidade com seu racionalismo, sua tecnocracia e sua crença em um progresso linear e verdades absolutas. Harvey (1992) acredita que após 1973 ocorreu uma aceleração nas mudanças de produção, trocas e consumo. Há uma troca de ênfase no 
capitalismo da produção de bens para a produção de eventos e espetáculos. Harvey (1992) salienta que as grandes histórias e as metanarrativas são combatidas pelo pós-modernismo, substituindo-as pela heterogeneidade e diferença.

Para Bauman (1998), a solidez e continuidade da modernidade foram substituídas pela incerteza não só em relação às pessoas, mas também em relação ao mundo e à forma adequada de se viver nele. Contudo, o que é novo na incerteza pós-moderna para Bauman (1998) é que ela não é algo inconveniente ou temporária, que poderia ser abrandada ou transposta, pois o "mundo pós-moderno está se preparando para a vida sob uma condição de incerteza que é permanente e irredutível" (BAUMAN, 1998, p. 32). Bauman (1998) enfatiza quatro características do mundo pós-moderno, denominado pelo autor de modernidade líquida: (1) nova desordem no mundo, onde países e blocos econômicos anteriormente vistos como hegemônicos e detentores do poder global perdem prestígio e força, (2) desregulamentação global por meio de uma liberdade desatada concedida ao capital, à custa de todas as outras liberdades, com o despedaçamento de redes de segurança social e o repúdio de qualquer razão não econômica, (3) enfraquecimento de redes sociais oferecidas pela família e comunidade e (4) meios de comunicação cultural com mensagem de indeterminação e maleabilidade do mundo. Bauman (2005) acredita que a centralidade do mundo de hoje está no consumo e que é em torno do consumo que os indivíduos criam máscaras identitárias que são trocadas a todo momento de acordo com a conveniência dos sujeitos. Diante do exposto, Bauman $(1998,2005)$ deixa claro que para ele a modernidade líquida pode ser definida como formas econômicas, existenciais, sociais e culturais instáveis.

Lyotard (2000) é o autor que mais restringe a abrangência do que seria pós-modernidade, restringindo apenas sua definição ao campo do conhecimento. Para ele pós-modernidade é um movimento que tem sua origem na ciência, principalmente no combate às metanarrativas. $\mathrm{O}$ autor ao analisar as condições do saber nas sociedades contemporâneas afirma sua ruptura com a modernidade. Essa ruptura se dá pelo combate ás grandes narrativas presentes, por exemplo, nos discursos emancipatórios. Vale ressaltar que, tanto para Lyotard (2000) quanto para Bauman (1998), a pós-modernidade não é o fim do modernismo, mas é um estado nascente do próprio modernismo, ou seja, a pós-modernidade é uma continuidade da modernidade.

Hall (2006) atribui o sentido de pós-modernidade à fragmentação, dedicando sua obra para entender os aspectos subjetivos inerentes à pós-modernidade. Ele evidencia que as sociedades contemporâneas têm passado por uma mudança estrutural que está fragmentando as paisagens culturais de classe, gênero, etnia, sexualidade e identidade nacional, que até então haviam servido como um sólido refúgio para os indivíduos. O autor denomina de "descentramento do sujeito" a crise de identidade provocada pela perda de um sentido estável e íntegro em relação ao conceito de sujeito. Hall (2006) entende como pós-modernidade esse movimento de perda identitária vivida pelos sujeitos. Para ele, o sujeito coerente, estável e unificado existente na modernidade é substituído pelo sujeito fragmentado e instável da pós-modernidade.

Por sua vez Jameson (1991) intenta evidenciar em seu trabalho um sentido histórico e econômico para a pósmodernidade, aproximando-se muito de (HARVEY, 1992). Ele diferencia pós-modernismo de modernismo ao relacionar pós-modernismo a um novo estágio histórico, sendo que Jameson (1991) se aproxima do marxismo ao fundamentar sua análise histórica no econômico. Para ele o pós-modernismo não é uma moda ou uma pausa radical em relação ao modernismo, mas sim uma cultura de dominação do capitalismo tardio. Para Jameson (1991), o pós-modernismo é uma expressão cultural de mudanças econômicas que ocorreram dentro do próprio capitalismo.

O econômico também ocupa uma posição de destaque na obra de Baudrillard (1986). A noção de commodities é o principal ponto para Baudrillard (1986), que diferencia a sociedade atual em relação ao capitalismo estudado em outras épocas. Para Baudrillard (1986), o capitalismo atual está preocupado com a produção de todo um sistema de sinais e signos ao invés de commodities. Para o autor, atualmente ocorre nas sociedades atuais um "simulacro". Como "simulacro" Baudrillard (1986) entende um estado permanente de replicação onde não se consegue saber o que é original do que não o é. Nesse sentido a identidade fica 
completamente dependente da replicação de identidades, sejam elas identidades corporativas, institucionais ou políticas, onde não se consegue diferenciar o real do não real.

Semelhantemente a Bauman (1998, 2005) e Lyotard (2000), Giddens (1991, 2002) acredita que a pósmodernidade, denominada por ele de modernidade tardia, é uma forma de expressão da própria modernidade, pois a modernidade não se resume apenas em uma vivência com mudanças cada vez mais rápidas, mas também é uma nova forma de refletirem as sociedades tradicionais para, assim, romper com o passado. Desta forma, Giddens entende como pós-modernidade o combate à tradição, aliás, fato que nos lembra Weber (1999), pois para Weber (1999) a sociedade burocrática industrial do século XIX tinha também como principal intento combater a tradição. Contudo, Giddens $(1991,2002)$ não limita ao econômico seu entendimento de pós-modernidade, pois para ele a globalização não se refere apenas a mudanças econômicas, mas também a alterações sociais e culturais.

Para Giddens (1991, 2002), a globalização provoca uma interconexão entre diversas partes e regiões do planeta, provocando movimentos de mudanças sociais, bem como transformações nas instituições modernas. Para o sociólogo estas mudanças de tempo-espaço produzem um "desalojamento do sistema social", no qual as relações sociais locais são reestruturadas ao longo de uma escala tempo-espaço indefinidas e descontínuas.

Por fim, Peters (2000) acredita que o pós-modernismo tem como objeto o modernismo, enquanto o pósestruturalismo tem como objeto teórico o estruturalismo. Neste sentido, o autor relaciona pós-modernismo como sendo um momento histórico. Peters (2000) esclarece que o pós-modernismo tem dois significados, ambos relacionados ao modernismo: (1) refere-se às mudanças nas artes que aconteceram em reação ao modernismo ou (2) significa período histórico ou ethos denominado de pós-modernidade, representando uma transformação da modernidade ou uma mudança radical em relação às práticas modernas. Diante destas duas definições, o autor defende que pós-modernismo é um ethos, um período histórico. Para ele, pósmodernismo tem sido muito frequentemente confundido com pós-estruturalismo, mas, embora ocorram sobreposições filosóficas e históricas entre estes dois movimentos, eles são movimentos distintos.

Diante do exposto algumas questões emergem: Seriam os conceitos sociológicos até então apresentados sobre pós-modernidade antagônicos e autoexcludentes? O pós-modernismo é um momento histórico ou apenas uma linha teórica de pensamento, ou ambos? Diante de tanta diversidade de ideias, existiria algo capaz de unificar o entendimento de pós-modernidade contido nos autores apresentados? Quais as relações do pós-estruturalismo e do estruturalismo com a pós-modernidade? Estas questões serão respondidas ao longo das próximas seções deste artigo.

\section{Pós-modernismo e Pós-estruturalismo: à noite todos os gatos são pardos}

Os conceitos sociológicos apresentados não são totalmente antagônicos e nem auto-excludentes. Por quê? Apesar das diferenças e direções de análise envolvendo a pós-modernidade entre os autores, pode-se afirmar que os conceitos são complementares e não antagônicos e excludentes. Quais seriam estes pontos comuns e complementares? (1) Verifica-se nos autores uma visão mais abrangente de pós-modernidade, pois, com exceção de Lyotard (2000), que foca sua visão pós-moderna no conhecimento, os demais autores entendem que pós-modernidade envolve ao mesmo tempo outros aspectos e não somente saberes, relacionando-a concomitantemente a aspectos econômicos, sociais, culturais, teóricos, políticos, subjetivos e existenciais, não caracterizando, assim, a pós-modernidade como algo relacionado exclusivamente ao campo do conhecimento. (2) Os autores defendem que pós-modernidade é um período histórico marcado por uma mudança em relação ao período moderno, seja essa mudança vista como parcial (BAUMAN, 1998, 2005; LYOTARD, 2000; GIDDENS, 1991, 2002; JAMESON, 1991) ou uma mudança marcada pela ruptura total conforme acreditam os demais autores. (3) Ao fazerem este movimento de comparação entre modernidade e pós-modernidade, enfatizando suas diferenças como momentos históricos e/ou ontológicos, os autores assumem e manifestam o caráter histórico da pós-modernidade, demonstrando que pós-modernidade está 
diretamente relacionada com modernidade, conforme salientou Peters (2000). Assim, pode-se afirmar que os autores analisaram a pós-modernidade como período histórico (ontologia) e não somente como episteme, intentando demonstrar sua influência em aspectos específicos da vida humana, como a globalização (GIDDENS, 1991, 2002; BAUMAN, 1998, 2005), as mudanças políticas (BAUMAN, 1998, 2005; SARUP, 1996), a relação tempo-espaço (SARUP, 1996; GIDDENS, 1991, 2002), a cultura (HALL, 2006; SARUP, 1996) e a economia (HARVEY, 1992; SARUP, 1996; JAMESON, 1991; BAUDRILLARD, 1986; LYOTARD, 2000; BAUMAN, 1998, 2005). Pode-se observar que os autores aparecem em mais de uma categoria de análise. Contudo, vale salientar que a influência da ontologia pós-moderna também afeta os saberes científicos relacionados ao campo do conhecimento (LYOTARD, 2000; HARVEY, 1992; JAMESON, 1991), mas que não se restringe apenas a ela, pois é algo maior do que apenas uma corrente teórica de pensamento.

Portanto, por ser um período histórico, a pós-modernidade estaria relacionada às mudanças produzidas na sociedade, quer sejam mudanças econômicas, sociais, culturais, geográficas, temporais, políticas, filosóficas, ou científicas. Desta forma, o conceito de pós-modernidade em Peters (2000) acaba embarcando todos os demais conceitos, pois pós-modernidade é para o autor algo bem mais amplo e envolve diversos aspectos da vida e não somente o conhecimento. Entretanto, existe uma tendência no campo organizacional de tratar pósmodernidade como uma corrente teórica de pensamento, uma episteme. Assim, neste momento pretendemos explicar as diferenças entre pós-modernidade e pós-estruturalismo para em seguida analisarmos como a pósmodernidade é utilizada nos estudos organizacionais.

Peters (2000, p. 9) salienta que pós-modernismo é frequentemente confundido com pós-estruturalismo e que, embora "haja sobreposições filosóficas e históricas entre os dois movimentos, é importante distingui-los para que possamos avaliar suas respectivas genealogias, trajetórias e aplicações". Peters (2000, p. 9) ainda afirma que pós-modernismo e pós-estruturalismo têm objetos teóricos completamente diferentes, pois o "pósestruturalismo toma como seu objeto teórico o 'estruturalismo', enquanto o pós-modernismo toma como seu objeto o "modernismo"'.

O autor defende ideia de que pós-modernidade é um movimento bem mais amplo do que apenas uma mudança estética no mundo das artes e do conhecimento, definindo pós-modernidade como um período histórico, uma ontologia. Já o pós-estruturalismo e o estruturalismo representariam transformações no campo do conhecimento, ou seja, são epistemologias. Portanto, apesar do pós-estruturalismo e estruturalismo serem influenciados pela pós-modernidade, eles não representam em sua totalidade a pós-modernidade, pois a pósmodernidade é algo maior, que não está somente circunscrita ao campo do conhecimento, envolvendo também transformações estéticas, sociais, culturais, políticas, econômicas, geográficas, dentre outras.

Para Peters $(1995,1996,2000)$, o pós-estruturalismo deve ser entendido como uma resposta filosófica específica contra o estruturalismo, resposta esta fortemente influenciada pelos trabalhos de Nietzsche (1976, 1993, 1998) e Heidegger $(2004,2006)$. O termo estruturalismo foi utilizado pela primeira vez por Jakobson (PETERS, 2000). O estruturalismo provocou uma guinada linguística no pensamento ocidental por meio das obras de Saussure (1993), Lévi-Strauss (1975), Althusser (1984), Lacan (2008) e Bourdieu (1990), sendo inclusive o trabalho de Foucault $(1996,2002,2003)$, em sua fase arqueológica, considerado estruturalista por Peters (2000) e Araújo (1993).

Araújo (1993) afirma que a análise estruturalista abrange setores diversos como a linguística, psicanálise, etnologia, filosofia e matemática. O autor cita Jakobson, Barthes, Lévi-Strauss, Piaget, Althuser e Foucault como exemplos de pensadores estruturalistas. Mas o que autores tão diferentes teriam em comum para serem denominados estruturalistas? Araújo (1993, p. 113) responde essa questão explicando que o solo comum é a linguística, pois por meio da linguística o estruturalismo acabou permeando outros domínios baseando-se na crença de que "só há estrutura na medida em que há linguagem, oposição, símbolo, diferenciação, capacidade de topologizar". 
Assim, a principal finalidade de qualquer pesquisa estruturalista "é conhecer o que há de universal no homem e que seja apreensível ou cognoscível pela ciência" (ARAÚJO, 1993, p. 124). Enquanto os marxistas trabalham com um método histórico/concreto (dialético), o estruturalismo baseia-se em um método ahistórico/formal (estrutura). Assim, o estruturalismo preocupa-se em conhecer a combinação de elementos que resultam na forma, sendo que, para obter a forma, faz-se necessário descortinar o sentido pelo qual a realidade é interpretada. Mas a realidade nunca contém por inteiro seu próprio sentido. Desta maneira, a principal contribuição do estruturalismo à filosofia e ao método nas ciências humanas, bem como a sua postura eminentemente crítica, é que formalizar é interpretar (ARAÚJO, 1993). Entretanto, isso não significa que a estrutura "seja fruto de uma consciência subjetiva. Aliás, é a própria estrutura que permite a articulação do sujeito. Assim como não há fala sem que haja língua, também não há sujeito sem que haja sistema pelo qual e no qual a possibilidade de um sujeito se constituir enquanto tal é dada" (ARAÚJO, 1993, p. 128).

Para Piaget (1974), toda estrutura possui as seguintes características: totalidade, transformação e autorregulação. Para Foucault (2000), o movimento estruturalista manifesta em seu conteúdo uma grande influência do movimento formalista europeu. O estruturalismo é uma resposta filosófica ao Humanismo, pois intenta romper com a noção de primado do sujeito contida no Humanismo e no existencialismo. O Humanismo tende a colocar o sujeito no centro de toda análise e teoria, "vendo-o como a origem e a fonte do pensamento e da ação, enquanto o estruturalismo [...] via os sujeitos como simples portadores de estruturas" (PETERS, 2000, p. 31).

O pós-estruturalismo é uma resposta filosófica à pretensão científica do estruturalismo em se tornar um megaparadigma para todas as ciências sociais. O pós-estruturalismo intenta descentrar as "estruturas" e toda a sistematicidade do estruturalismo, questionando a metafísica presente no estruturalismo, mas mantendo os elementos principais relacionados à crítica que o estruturalismo faz ao sujeito humanista (PETERS, 1996, 2000). Vale ressaltar dois pontos comuns entre pós-estruturalismo e estruturalismo: (1) ambos manifestam uma reação filosófica à forma moderna de se fazer ciência e à noção de sujeito Iluminista, (2) o pósestruturalismo também é fundamentado na tradição estruturalista da linguística. Assim, tanto estruturalismo e pós-estruturalismo são manifestações filosóficas relacionadas ao conhecimento (epistemologias) que emergem em um período histórico pós-moderno (ontologia). Peters $(2000$, p. 28) esclarece que o "pósestruturalismo é uma crítica ao estruturalismo, feita a partir de seu interior", ou seja, apesar das diferenças existem relações entre estruturalismo e pós-estruturalismo.

A Psicologia Social dedicou-se a analisar o que seria o sujeito para o estruturalismo e para o pósestruturalismo. Principalmente ao definir o que é construcionismo e construtivismo, a Psicologia Social contribuiu muito para o entendimento de que tanto o estruturalismo quanto o pós-estruturalismo são perspectivas teóricas que ganham espaço somente na pós-modernidade. Apesar das diferentes formas de construcionismo e construtivismo, pode-se afirmar que as abordagens construtivistas do sujeito são abordagens estruturalistas, como Piaget (1974), por exemplo. Já as abordagens construcionistas podem ser representadas pelo pós-estruturalismo, dentre outras abordagens. Contudo, não se objetiva neste artigo entender a definição de sujeito nestas abordagens e sua influência nos estudos organizacionais, algo que demandaria a construção de um artigo específico para este fim devido à complexidade do tema, bem como por esta análise já ter sido realizada nos estudos organizacionais por Peci (2003), Paula, Maranhão e Barros (2009) e Peci e Alcadipani (2006).

O importante aqui é trazer à tona que o estruturalismo também é uma abordagem do conhecimento emergida na pós-modernidade e influenciada pela ontologia pós-moderna. O interessante é evidenciar que tal fato é negligenciado pelos estudiosos organizacionais, pois tendem a considerar somente o pós-estruturalismo como tendo alguma relação com o pós-modernismo. Parece que no transpassar da Psicologia Social para a Administração os conceitos pós-modernos relacionados ao estruturalismo foram encobertos pelos estudiosos organizacionais. Ao analisar os textos da Psicologia Social sobre o tema, pode-se claramente demonstrar que o estruturalismo é uma concepção teórica que traz preocupações e questionamentos que só fazem sentido dentro da pós-modernidade. 
Por exemplo, Arendt (2003, p. 6, grifo nosso), ao responder quais as contribuições teóricas que abordagens pós-modernas podem dar à Psicologia Social, afirma que "o construcionismo e o construtivismo, ambos movimentos teóricos passíveis de serem classificados como pós-modernos, caminham em direções opostas: um, para o 'sociologismo'; outro, para o 'psicologismo"'. Botelha (2011) e Speed (1991) também caminham na mesma direção afirmando que o construtivismo (estruturalismo) compartilha dos mesmos princípios teóricos que constituem e caracterizam a pós-modernidade.

Mas, se estruturalismo e pós-estruturalismo são movimentos que tomam força em um contexto histórico pósmoderno e sendo o pós-estruturalismo um movimento que nasce dentro do próprio estruturalismo, quais seriam as características que os diferenciam? Se o estruturalismo é a-histórico em sua busca em apagar a história por meio do estudo das estruturas, o pós-estruturalismo trabalha com uma perspectiva de uma história crítica, concentrando-se na mudança, na transformação, na ruptura, na genealogia e na descontinuidade das estruturas (PETERS, 2000). O pós-estruturalismo problematiza e questiona o cientificismo das ciências humanas, adotando um posicionamento epistemológico antifundacionista, enquanto o estruturalismo é fundacionista. Por fim, o pós-estruturalismo questiona aspectos relacionados ao racionalismo e realismo que o estruturalismo retomou do positivismo por meio de sua crença no progresso e na capacidade emancipatória e transformadora, "colocando em dúvida, além disso, a pretensão estruturalista de identificar as estruturas universais que seriam comuns a todas as culturas e à mente humana em geral" (PETERS, 2000, p. 39).

Diante do exposto ficam claras as relações existentes entre o estruturalismo e o pós-estruturalismo, bem como suas divergências. Estruturalismo e pós-estruturalismo têm em comum serem movimentos que se potencializam em um contexto histórico pós-moderno, compartilham o rompimento com uma definição de sujeito Humanista, combatem a filosofia Humanista e atribuem uma grande importância à linguística. O que os afasta é a crítica pós-estruturalista ao fundacionismo, a busca de estruturas universalizantes, a metafísica, a crença no progresso e a busca da emancipação.

Conforme já salientado, não se pode falar que pós-modernismo somente expresse em sua ontologia questões ligadas ao conhecimento, pois sendo um período histórico, um ethos, sua abrangência e influência vai além dos domínios do conhecimento científico e filosófico. Entretanto, pode-se afirmar que o estruturalismo e o pós-estruturalismo são movimentos epistemológicos historicamente pós-modernos. Tendo-se explicado as relações entre pós-modernismo, pós-estruturalismo e estruturalismo, resta-nos agora entender como o pósmodernismo é tratado nos estudos organizacionais.

\section{Pós-modernismo nos Estudos Organizacionais}

Vale de antemão ressaltar que nos estudos organizacionais tem ocorrido uma grande confusão envolvendo o pós-estruturalismo e o pós-modernismo. A maioria dos trabalhos organizacionais tende a tratar pósestruturalismo como sinônimo de pós-modernismo e vice-versa. Por exemplo, Alvesson e Deetz (1998) utilizam conceitos pós-estruturalistas, mas os denominam de pós-modernos, chegando até a afirmarem que Foucault, Derrida, Deleuze, Guattari são autores pós-modernos. O uso indevido por parte de Alvesson e Deetz (1998) do termo pós-modernismo também foi observado por Paula $(2009$, p. 4). Ela afirma que “[...] seria correto restringir o 'pós-modernismo' a um conjunto de abordagens filosóficas e autores, se estes não fossem representantes na verdade do pós-estruturalismo, termo muito mais preciso do que 'pós-modernismo' para designar esta corrente".

Segundo Alvesson e Deetz (1998), o pós-modernismo pode ser entendido de duas maneiras: (1) um clima social, um período histórico caracterizado por mudanças sociais e econômicas, ou (2) um conjunto de abordagens filosóficas relacionadas ao estudo da organização e das demais áreas. É a segunda definição que Alvesson e Deetz (1998) adotam para explicar o que é pós-modernidade, afirmando que a pós-modernidade intenta combater metanarrativas e afirmar o descentramento do sujeito. 
Alvesson e Deetz (1998) definem pós-modernidade como uma epistemologia que rompe com a ideia de neutralidade científica, igualando o movimento científico ao político. Para eles o pesquisador pós-moderno é um agente social e historicamente situado e não um sujeito autônomo e livre, privilegiando as narrativas locais e o conhecimento prático, evitando a construção de metanarrativas. Na realidade estas características pertencem ao pós-estruturalismo, salientando-se que o rompimento com a ideia Humanista de sujeito autônomo está presente tanto no estruturalismo quanto no pós-estruturalismo, o que enfatiza e evidencia a influência histórica (ontológica) da pós-modernidade sobre estas correntes do pensamento. Talvez devido a esse equívoco Alvesson e Deetz (1998) definam Foucault, Deleuze, Guattari e Derrida como sendo representantes de uma corrente teórica denominada pós-moderna por eles, enquanto de fato, em termos epistemológicos, são pós-estruturalistas e não pós-modernos. $\mathrm{O}$ que se quer evidenciar aqui é que não se pode caracterizar a pós-modernidade como uma forma específica de corrente teórica, pensamento, conhecimento ou episteme. Pós-modernidade deve ser entendida como uma ontologia, um momento histórico, um ethos, e, nesse sentido, se formos considerar a influência do momento histórico na constituição dos saberes, poderíamos até considerar o pós-estruturalismo como uma das manifestações no campo do saber que emergiu em um contexto histórico pós-moderno, chamando pós-estruturalismo de "pós-moderno" apenas para demarcar este contexto histórico relacionado à sua constituição. Vale ressaltar que pósmodernidade é algo bem mais amplo do que apenas um movimento epistemológico, envolvendo aspectos culturais, econômicos, sociais, políticos, étnicos, artísticos, tempo-espaço e estéticos, dentre outros (PETERS, 2000).

Ora, se tanto pós-estruturalismo e estruturalismo são movimentos do campo do conhecimento que só se tornam visíveis em uma ontologia pós-moderna (Arendt, 2003; Botella, 2011; Speed, 1991), não se pode afirmar que todo conhecimento emergido na pós-modernidade combata as metanarrativas, pois nem todo conhecimento gerado na ontologia pós-moderna é um movimento de combate às metanarrativas. Por exemplo, o estruturalismo também emerge na pós-modernidade, mas não visa ao combate de metanarrativas e nem prega a fragmentação do sujeito.

Hatch (1997), ao dividir os estudos organizacionais em três campos epistemológicos: modernismo, simbolismo e pós-modernismo, também não avança muito no esclarecimento sobre o que seria pósmodernidade nos estudos organizacionais. Hatch (1997) considera Foucault, Derrida, Bakhtin, Lyotard, Baudrillard exemplos de autores pós-modernos. Ao afirmar que os autores pós-modernos são relativistas no sentido em que abandonam a noção de um critério universal para entenderem os fenômenos, a autora trata pós-modernidade como se fosse um campo específico do conhecimento muito similar ao que faz Alvesson e Deetz, chegando a caracterizar a pós-modernidade como uma teoria neo-marxista.

Outra questão parece-nos pertinente nesse momento: será que todas as teorias consideradas pós-modernas por Hatch (1997) trabalham com o conceito de desconstrução, conforme afirma a autora? Não. Enquanto Derrida (2004) trabalha com o conceito de desconstrução, Foucault (1979) critica qualquer classificação de sua obra como desconstrucionista, preferindo trabalhar com genealogias ao invés de desconstruções. Além disso, ambos são epistemologicamente teóricos pós-estruturalistas e não pós-modernos como Hatch (1997) os trata.

Cooper e Burrel (2007) tratam a pós-modernidade como uma manifestação ocorrida nas ciências humanas em seu momento de autoanálise e autodúvida. Para eles pós-modernidade é uma concepção ontológica conflitante com o modernismo, principalmente pela sua crença na capacidade humana de progredir por meio do pensamento racional e antropocêntrico. Ao fazerem a comparação entre modernismo e pós-modernismo, verifica-se que os autores manifestam o caráter histórico da pós-modernidade, pois, conforme Peters (2000) já havia salientado, a modernidade e a pós-modernidade estão no mesmo plano, ou seja, no plano histórico e ontológico, e, somente sendo tratadas no mesmo plano, podem ser comparadas entre si. Os autores deixam claro que, ao classificarem Lyotard, Derrida, Foucault e Deleuze como pós-modernos, estão empregando este termo em seu sentido ontológico e histórico e não no sentido epistemológico, principalmente ao esclarecem que os classificam como pós-modernos pelo fato de eles rejeitarem a noção de um agente humano central no 
processo do controle racional e do entendimento, rejeitando o racionalismo etnocêntrico proposto pelo modernismo.

Parker (1995) acredita que a pós-modernidade é um projeto que abandona as noções de verdade e progresso, apresentando sua definição de pós-modernidade como sendo um combate às teorias Iluministas/Humanistas com suas crenças na verdade e no progresso. Contudo, Parker (1995) não considera Foucault e Derrida autores pós-modernos, mas sim pós-estruturalistas, atribuindo a classificação pós-moderna a Lyotard e Baudrillard. Contudo, apesar de conseguir enxergar que Foucault e Derrida não são pós-modernos, Parker (1995) coloca o pós-modernismo e o pós-estruturalismo no mesmo patamar, como sendo duas tradições teóricas de pensamento, limitando a abrangência do pós-modernismo somente ao campo do conhecimento, não enxergando o pós-modernismo como um ethos.

Hassard (1993) considera o pós-modernismo um novo paradigma para a teoria organizacional, defendendo que pós-modernismo pode ser descrito ou como uma "época", ou como uma "epistemologia". Para Hassard (1993), o pós-modernismo prega a "morte da razão". Ele afirma que o método pós-moderno de desconstrução rompe com as noções de unidade de significado, de teoria e de self. Nesse aspecto Hassard (1993, p. 111, tradução nossa) afirma que:

A primeira característica do pós-modernismo, portanto, é que ele rejeita a noção que referência é, ou pode ser, uma relação unívoca entre formas de representação (palavras, imagens, etc.) e um objeto, mundo externo. No nível pós-moderno de análise o foco é sobre 'as regras que fundamentam as práticas as quais procedem à subjetividade, sendo a teoria estruturalista fundamental nesse propósito de ataque contra a consciência.

Interessante esta citação de Hassard (1993), pois ele é o único autor organizacional a considerar o estruturalismo uma episteme pertencente à ontologia pós-moderna. Para ele a emergência de uma nova totalidade social pós-moderna está implícita nos escritos de Baudrillard e Lyotard. Hassard (1993) afirma que nos estudos organizacionais Clegg entende pós-modernidade como uma época histórica, já Cooper e Burrell tem uma posição epistemológica de pós-modernidade. Para Hassard (1993), o conflito entre definição histórica ou epistemológica deve ser solucionado pela adoção de um meio termo entre essas duas definições. Contudo, em outro artigo escrito em coautoria, Hassard parece privilegiar questões históricas em detrimento dos aspectos epistemológicos em seu conceito de pós-modernidade (HASSARD, TONELLI e ALCADIPANI, 2000).

Kilduff e Mehra (1997) salientam a falta de clareza do termo pós-modernismo nos estudos organizacionais, onde geralmente é tratado como significasse desconstrução e visto como um empreendimento niilista que não tem nada a oferecer para o campo organizacional com seu asceticismo. Os autores tratam pósmodernismo como sendo uma epistemologia, dividindo-o em duas perspectivas de análise: ascética e afirmativa. Na abordagem ascética toda forma de interpretação de um fenômeno é igualmente válida, e o mundo é tão complicado que conceitos como predição e causalidade são irrelevantes, oferecendo uma visão pessimista e negativa de qualquer possibilidade das ciências sociais. Já a abordagem afirmativa possibilita o comprometimento com padrões rigorosos de pesquisa sem perder sua interpretação radical, trazendo reflexividade e riqueza em sua diferença e seu foco no singular. Para eles a perspectiva afirmativa é a única forma viável de pesquisa pós-moderna nas organizações, sendo que os autores colocam o desconstrucionismo de Derrida como principal interlocutor desta perspectiva. Kiduff e Mehra (1997) defendem o uso de técnicas, métodos e abordagens de diversas tradições nas pesquisas afirmativas pósmodernas, inclusive trabalhos que utilizem a noção de progresso e métodos tradicionalmente associados ao positivismo.

Para Alvarado (1996) as palavras pós-modernismo e pós-modernidade têm significados distintos. Pósmodernismo refere-se aos teóricos e teorias sobre pós-modernidade. Já pós-modernidade é um período histórico, sendo a condição pós-moderna uma consequência da evolução moderna. Alvarado (1996) trata o 
tema de forma bem semelhante a Hassard (1993), pregando a união entre epistemologia (pós-modernismo) e ontologia (pós-modernidade). Contudo, a principal preocupação de Alvarado (1996) é estender o conceito de pós-modernidade para a materialidade funcional das organizações. Para ele, a preocupação prática/empírica em se construir organizações com estruturas funcionais pós-modernas não pode ficar localizada exclusivamente em países industrializados, pois provocaria uma nova forma de colonialismo em relação a organizações do terceiro mundo.

Segundo Calás e Smircich (1999), a partir de 1970 surgiram diversas perspectivas teóricas nas ciências sociais e nos estudos organizacionais que compartilhavam as seguintes características: preocupação com a linguagem e representação, reconsideração da subjetividade e do poder e combate às metanarrativas, sendo pós-modernismo o nome utilizado para rotular todas as perspectivas teóricas que possuem estas características. Calás e Smircich (1999) afirmam que o pós-estruturalismo é uma das diversas perspectivas teóricas pós-modernas, ou seja, elas tratam pós-estruturalismo como uma epistemologia que surge na era pós-moderna. Calás e Smircich (1999) consideram a teoria feminista pós-estruturalista, a teoria ator-rede, a análise pós-colonial e as abordagens narrativas como correntes teóricas que representam o momento histórico pós-moderno. Da mesma forma que Parker (1993), Calás e Smircich (1999) classificam Foucault e Derrida como pós-estruturalistas.

Nos estudos organizacionais brasileiros, Vieira e Caldas (2006) adotam uma posição bem próxima a Alvesson e Deetz (1998) para definirem pós-modernidade, tratando-a como um campo do conhecimento que se opõe às crenças modernistas iluministas. Para Vieira e Caldas (2006), Derrida, Lyotard e Foucault seriam exemplos de pensadores pós-modernos. Para Leal (2002), vasta parte da teoria organizacional é apoiada nos vigamentos modernistas da racionalidade individual e do empirismo sistemático. Segundo Leal (2002, p. 83), "Os pesquisadores organizacionais não podem desconhecer, por um lado, o traço marcante de racionalidade e empirismo presente nos estudos organizacionais, contribuição da modernidade [...]. Tampouco podem ignorar as críticas dos pesquisadores pós-modernos". Para ele as abordagens pós-modernas não têm sido capazes de nortear os estudos organizacionais e, para resolver este impasse, propõe a inclusão de uma terceira matriz que atuaria de forma conciliatória entre as epistemologias modernas e pós-modernas. Esta matriz seria representada pela dimensão estética, salientando-se que para o autor ética e estética são duas faces da mesma moeda.

Tenório (2009) enfatiza que o conceito de pós-modernidade só começa a ser debatido com intensidade a partir da década de setenta com o advento da obra de Lyotard (2000). A forma de escrita do artigo de Tenório (2009) é bem interessante e aproxima-se das artes literárias. Contudo, o principal objetivo do autor não é aprofundar as discussões e conceitos sobre pós-modernidade, tendo como intento principal de seu artigo uma revalorização das ideias da escola de Frankfurt, principalmente as de Habermas, as quais a modernidade não está morta com o advento da pós-modernidade, principalmente a busca pela emancipação do homem.

\section{Estudos organizacionais: equívocos relacionados ao pós-modernismo}

Observam-se os seguintes equívocos nos estudos organizacionais relacionados à pós-modernidade: (1) definir pós-modernidade como uma epistemologia; (2) tratar pós-estruturalismo como sinônimo de pósmodernidade e vice-versa; (3) atribuir características à pós-modernidade que na realidade dizem respeito apenas ao pós-estruturalismo; (4) desconsiderar o estruturalismo como pertencente à ontologia pós-moderna.

A definição de pós-modernidade como uma corrente de pensamento, um movimento filosófico e científico, ou seja, uma epistemologia está presente nas obras de Alvesson e Deetz (1998), Hatch (1997), Kiduff e Mehra (1997), Parker, (1995), Vieira e Caldas (2006) e Leal (2002). Aliás, Hassard (1993) e Alvarado (1996) são os únicos que não trabalham com essa concepção de pós-modernidade nos estudos organizacionais, adotando uma posição conciliatória, na qual pós-modernidade representaria ao mesmo 
tempo época histórica (ontologia) e tradição teórica (epistemologia). Conforme salientado, o problema não é classificar um determinado autor como pós-moderno, pois, desde que esta classificação deseje apenas afirmar e salientar a influência da condição histórica pós-moderna na construção de seu pensamento, não há nenhum equívoco em denominá-lo de pós-moderno, ressaltando-se que neste caso pós-modernidade deve ser entendida como ontologia, ethos, momento histórico. O problema de classificar um autor como pós-moderno é atribuir a esta classificação um sentido epistemológico, pois, conforme já evidenciado, a pós-modernidade envolve diversos aspectos da vida humana e não pode ser concebida apenas como movimento teórico. Desta forma, pós-modernidade não pode ser vista como epistemologia, visão esta presente na maioria dos autores organizacionais, mas sim como ontologia.

O combate às metanarrativas não é uma característica do pós-modernismo como afirmam Alvesson e Deetz (1998) e Calás e Smircich (1999), mas do pós-estruturalismo. Nem todos saberes que emergiram em um contexto histórico pós-moderno pregam o fim das metanarrativas, pois o estruturalismo é uma abordagem emergente na pós-modernidade e não tem como pretensão combater metanarrativas (PETERS, 2000; HASSARD, 1993). Esse equívoco contribui para que os autores organizacionais tendam a atribuir aos conceitos pós-estruturalistas o rótulo de pós-moderno no sentido epistemológico do termo, como fazem Hatch (1997), Kiduff e Mehra (1997), Alvesson e Deetz (1998), Vieira e Caldas (2006), Calás e Smircich (1999). O que o estruturalismo e pós-estruturalismo, ambos movimentos epistemológicos da era pósmoderna, têm em comum não é o combate às metanarrativas, mas o fim do sujeito antropológico racional e autônomo e o uso da linguística.

\section{Para Além da Conclusão}

Os debates sobre o que é pós-modernidade nos estudos organizacionais brasileiros ainda são tímidos e baseiam-se, em sua maioria, nos escritos de Alvesson e Deetz (1998). Este fato tem contribuído para a produção de muitos equívocos, conflitos e dilemas relacionados à pós-modernidade. Contudo, não se pretende neste artigo esgotar toda a discussão sobre o significado de pós-modernidade nos estudos organizacionais. Intentou-se aqui contribuir com este debate por meio da problematização acerca do tema, fundamentando sua análise em uma visão histórica de pós-modernidade, defendendo-se que pósestruturalismo e estruturalismo são exemplos de movimentos no campo do saber, influenciados pela ontologia pós-moderna. Ao se considerar uma abordagem teórica como pós-moderna, deve-se ter o entendimento que tal consideração afirma somente a presença das contingências históricas pós-modernas na produção e constituição deste saber e não considera pós-modernidade como significando corrente teórica de pensamento, epistemologia.

Não se pode caracterizar a pós-modernidade lhe atribuindo unicamente características relacionadas ao pósestruturalismo, pois pós-modernidade é um movimento bem mais amplo e não se refere exclusivamente ao campo do conhecimento, estendendo-se a outros aspectos da vida humana, sejam esses aspectos políticos, econômicos, sociais, temporais e espaciais. Salienta-se que, de acordo com o demonstrado, não se pode afirmar que; conforme fazem a maioria dos autores organizacionais (ALVESSON e DEETZ, 1998; VIEIRA e CALDAS, 2006; HATCH, 1997; COOPER e BURRELL, 2007; HASSARD, 1993), Foucault, Derrida, Deleuze, Baudrillard e Guattari são pós-modernos.

Desta forma, há um equívoco nos estudos organizacionais ao considerar o Pós-modernismo uma corrente teórica de pensamento (VIEIRA e CALDAS 2006; PARKER, 1995; ALVESSON e DEETZ, 1998; HATCH, 1997; CALÁS e SMIRCICH, 1999; LEAL, 2002) ao invés de uma época ou período histórico que influencia todo ethos social. Ao cometerem esse equívoco, os autores acabam atribuindo ao pós-modernismo características que são do pós-estruturalismo, sendo este sim um campo específico do conhecimento. Assim, relacionando ao pós-modernismo características e elementos pertencentes ao pós-estruturalismo, os autores organizacionais excluem e deixam de enfatizar em suas obras o potencial de outro movimento do saber 
emergente na pós-modernidade: o estruturalismo. Tal exclusão enfraquece a discussão sobre as alternativas ao funcionalismo, deixando de fora do debate organizacional autores estruturalistas.

Portanto, como sugestão de novas análises nos estudos organizacionais, salienta-se a importância de uma análise mais profunda acerca da relação existente entre estruturalismo e pós-estruturalismo, ao invés de tratálos como movimentos independentes e isolados. Desta forma, devem-se intensificar os debates acerca das obras de autores pós-estruturalistas, principalmente os trabalhos de Foucault, Derrida, Deleuze e Guattari, bem como de estudiosos estruturalistas, dentre eles pode-se citar Althusser, Lacan, Lévi-Strauss e Bourdieu, além das possíveis relações entre estes dois movimentos.

\section{Referências}

ALTHUSSER, L. Freud e Lacan, Marx e Freud: introdução crítica-histórica. Rio de Janeiro, 1984.

ALVARADO, F. Concerning postmodernity and organizations in the third world: opening a debate and suggestions for a research agenda. Organization Science, v. 7, n. 6, p. 667-681, nov/dec, 1996.

ALVESSON, M., DEETZ, S. Teoria crítica e abordagens pós-modernas para estudos organizacionais. In: CLEEG, S., HARDY, C., NORD, W. R. Handbook de estudos organizacionais. São Paulo: Atlas, 1998.

ARAÚJO, I. L. Introdução à filosofia da ciência. Curitiba: Ed. da UFPR, 1993.

ARENDT, R. J. J. Construtivismo ou construcionismo? Contribuições deste debate para a psicologia social. Estudos de Psicologia, v. 8, n. 1, p. 5-13, 2003.

BAUDRILLARD, J. Pour une critique de l'économie politique du signe. Paris: Gallimard, 1986.

BAUMAN, Z. O mal-estar da pós-modernidade. Rio de Janeiro: Jorge Zahar, 1998.

Identidade: entrevista a Benedetto Vechi. Rio de Janeiro: Jorge Zahar, 2005.

BOTELHA, L. Personal construct psychology, constructivism and postmodern though. Disponível em < http://www.massey.ac.nz/ alock/virtual/Construc.htm>. Acesso em: 22 dez. 2011.

BOURDIEU, P. Coisas ditas. São Paulo: Brasiliense, 1990.

CALÁS, M. B.; SMIRCICH, L. Past Postmodernism? Reflections and tentative directions. The Academy of Management Review, v. 24, n. 4, p. 649-671, 1999.

COOPER, R.; BURRELL, G. Modernismo, pós-modernismo e análise organizacional: uma introdução. In: CALDAS, M. P.; BERTERO, C. O. (Coords.). Teoria das Organizações. São Paulo: Atlas, 2007.

DERRIDA, J. Gramatologia. São Paulo, Perspectiva, 2004.

FOUCAULT, M. Microfísica do poder. Rio de Janeiro: Edições Graal, 1979.

A ordem do discurso. São Paulo: Edições Loyola, 1996.

Estruturalismo e Pós-estruturalismo. In: MICHEL, F. A arqueologia das ciências e história dos sistemas de pensamento. Rio de Janeiro: Forense Universitária, 2000.

A arqueologia do saber. Rio de Janeiro: Fontes Universitária, 2002.

A história da loucura. São Paulo: Editora Perspectiva, 2003. 
GIDDENS, A. As conseqüências da modernidade. São Paulo: UNESP, 1991.

Modernidade e identidade. Rio de Janeiro: Jorge Zahar, 2002.

HALL, S. A identidade cultural na pós-modernidade. Rio de Janeiro: DP\&A, 2006.

HARVEY, D. A condição pós-moderna: uma pesquisa sobre as origens da mudança cultural. São Paulo: Loyola, 1992.

HASSARD, J. Postmodernism and organization. In: Sociology and organization theory. Cambridge: Cambridge University Press, 1993.

. ; TONELLI, M. J.; ALCADIPANI, R. Pós-modernidade, teoria organizacional e o self do gerente minuto. Em: ENEO, 2000, Curitiba. Trabalhos apresentados, Paraná, 2000.

HATCH, M. J. Organization theory: modern, symbolic, and postmodern perspectives. Oxford: Oxford University Press, 1997.

HEIDEGGER, M. A caminho da linguagem. Petrópolis: Vozes, 2004.

2006.

Os conceitos fundamentais da metafísica: mundo, finitude, solidão. Rio de Janeiro: Forense Universitária,

JAMESON, F. Postmodernism, or the cultural logic of late capitalism. London: New York, 1991.

KILDUFF, M.; MEHRA, A. Postmodernism and organizational research. The Academy Of Management Review, v. 22, n. 2, p. 453-481, 1997.

LACAN, J. Escritos. Rio de Janeiro: Zahar, 2008.

LEAL, R. S. As dimensões da racionalidade e os estudos organizacionais: a mediação entre a modernidade e a pósmodernidade. O\&S, v.9, n. 25, p. 77-91, set./dez., 2002.

LÉVI-STRAUSS, C. Antropologia estrutural. Rio de Janeiro: Edições Tempo Brasileiro, 1975.

LYOTARD, J-F. A condição pós-moderna. Rio de Janeiro: J. Olympio, 2000.

NIETZSCHE, F. W. A gaia ciência. São Paulo: Hemus, 1976.

O nascimento da tragédia ou helenismo e pessimismo. São Paulo: Companhia das Letras, 1993.

Genealogia da moral. São Paulo: Companhia das Letras, 1998.

PAULA, A. P. P. “O que o handbook não diz": novas considerações sobre teoria crítica e abordagens pós-modernas para estudos organizacionais. Em: ENANPAD, XXXIII, 2009, São Paulo. Trabalhos apresentados, São Paulo, 2009.

.; MARANHÃO, C. M. S. A; BARROS, A. N. Pluralismo, pós-estruturalismo e "gerencialismo engajado": os limites do movimento critical management studies. Cad. EBAPE.BR, v. 7, n. 3, p. 392-404, set., 2009.

PARKER, M. Critique in the name of what: postmodernism and critical approaches to organization. Organization Studies, v. 16, n. 4, p. 553-564, 1995.

PECI, A. Estrutura e ação nas organizações: algumas perspectivas sociológicas. RAE, v. 43, n. 1, p. 24-35, jan/mar, 2003.

.; ALCADIPANI, R. Demarcação científica: uma reflexão crítica. O\&S, v. 13, n. 36, jan./mar., 2006.

PETERS, M. Education and the postmordern condition. Londres: Bergin \& Garvey, 1995. 
Poststructuralism, politics and education. Londres: Bergin \& Garvey, 1996.

Pós-estruturalismo e filosofia da diferença. Belo Horizonte: Autêntica, 2000.

PIAGET, J. O estruturalismo. São Paulo: Difel, 1974.

SARUP, M. Identity, culture and the postmodern world. Georgia: The University of Georgia Press, 1996.

SAUSSURE, F. Curso de linguística geral. São Paulo: Cultrix, 1993.

SPEED, B. Reality exists O.K.? An argument against constructivism and social constructionism. Family Therapy, v. 13, p. 395-4009, 1991.

TENÓRIO, F. G. A modernidade e a pós-modernidade servidas em dois jantares. Cad. EBAPE.BR, v. 7, n. 3, p. 472491, set., 2009.

VIEIRA, M. M. F.; CALDAS, M. P. Teoria crítica e pós-modernismo: principais alternativas à hegemonia funcionalista. RAE, v. 46, n. 1, p. 59-70, jan/mar, 2006.

WEBER, M. Economia e Sociedade: fundamentos da sociologia compreensiva. Brasília: Editora Universidade de Brasília. v.2., 1999. 